\title{
A PLURIDIMENSIONALIDADE DO LÉXICO EM PRÁTICAS DE ENSINO DE PORTUGUÊS
}

\author{
BEATRIZ DARUJ GIL ${ }^{1}$
}

\author{
Faculdade de Filosofia, Letras e Ciências Humanas \\ Universidade de São Paulo. Av. Luciano Gualberto, 403 - São Paulo - SP - Brasil
}

biagileusp.br

\begin{abstract}
Resumo. A partir da releitura da classificação das atividades lexicais de Oxford e Scarcella (1994), analisam-se, neste artigo, exercícios de vocabulário em materiais didáticos de português língua estrangeira (PLE) $e$ português língua materna (PLM) e, em seguida, apresenta-se uma prática de leitura, com ênfase no caráter pluridimensional do léxico, na qual são destacados os traços semânticos, morfossintáticos e discursivos de unidades lexicais, com o objetivo de demonstrar que a competência lexical se desenvolve por meio do conhecimento pluridimensional da palavra, diferentemente da tradição de ensino de léxico que sempre esteve concentrada no princípio da equivalência lexical.
\end{abstract}

Palavras-chave: léxico; competência lexical; equivalência lexical.

\begin{abstract}
From the reinterpretation of categorization of lexicon activities of Oxford and Scarcella (1994), in this article vocabulary activities are analyzed in teaching materials of Portuguese as a native language and Portuguese as a foreign language. Then a vocabulary teaching practice is presented, with an emphasis on the lexicon multidimensional character, in which semantic, morphosyntactic and discursive features of lexical units are highlighted in order to demonstrate that lexical competence is developed by means of multidimensional knowledge of the word, unlike the lexicon teaching tradition that has always focused on the principle of lexical equivalence.
\end{abstract}

Keywords: lexicon; lexical competence; lexical equivalence.

\section{Introdução}

Apesar de a lexicologia tratar do lexema em suas relações com a etimologia, a morfologia, a fonologia e a sintaxe, ela sempre priorizou a intersecção entre léxico e semântica, tendo estado mais focada nos aspectos semânticos da unidade lexical ${ }^{2}$, e na

\footnotetext{
${ }^{1}$ Doutora em Linguística pela USP. Docente na Faculdade de Filosofia Letras e Ciências Humanas (USP), na área de Filologia e Língua Portuguesa, atuando na Graduação e na Pós-Graduação.

${ }^{2}$ Utiliza-se o termo unidade lexical para se referir à unidade do léxico de maneira genérica, sem que se especifique se se trata da unidade no nível do sistema, da norma ou da fala. Para tratar dessa mesma unidade no nível do sistema, utiliza-se o termo lexema e, no nível do discurso, o termo lexia.
} 
descrição e análise do valor dos signos linguísticos. Essa especial ligação com a semântica fez com que se organizasse uma tradição de estudos léxicos concentrada na análise do significado das unidades léxicas, no nível do paradigma e do sintagma; nas relações semânticas tradicionais, como sinonímia, antonímia, ambiguidade; e na semântica histórica (VILELA, 1994).

O sentido lexical depende também da interação entre os signos, e entre signos e enunciadores, em cada prática única de enunciação, quando o lexema (unidade lexical do nível do sistema) ganha status de escolha lexical. Além de estocar significados advindos de recortes culturais, cada escolha contem intenções de seus interlocutores, definidas na constituição do discurso, o que a caracteriza como uma propriedade discursiva.

Nas tradicionais práticas de ensino do léxico, o aspecto semântico foi sempre o mais explorado, geralmente por meio de listas de palavras e exercícios de sinonímia. São práticas que, muitas vezes, desconsideram que o conteúdo semântico também depende das relações paradigmáticas, sintagmáticas e discursivas que a unidade lexical estabelece no uso.

Na maioria dessas práticas, o léxico costuma ser tratado separadamente da gramática. Em outros casos, ele é inserido dentro de um tópico gramatical, sem que se demonstrem suas relações com a gramática. Com espaço reduzido para o estudo do léxico, o que mais se enfatiza, nas aulas de língua portuguesa como língua materna é o ensino da metalinguagem como fim em si mesmo, a classificação gramatical (UCHÔA, 2009) e, na língua estrangeira, a gramática como forma de comunicação correta e a apresentação de palavras fora de contexto (RODRIGUES, 2007).

Tendo como ponto de partida uma leitura crítica da classificação de atividades de ensino do léxico de Oxford e Scarcella (1994), divididas em descontextualizadas, parcialmente contextualizadas e plenamente contextualizadas, apresenta-se, neste artigo, a análise de exercícios de léxico extraídos de livros didáticos de português língua estrangeira (doravante PLE) e de português língua materna (doravante PLM), à qual se segue uma prática de leitura, cujo objetivo é destacar a pluridimensionalidade do léxico, com base nos fundamentos de Leffa (1999, 2000) Nation (1990), Oxford e Scarcella (1994), Rio-Torto (2006) e Scaramucci (2007).

\section{Leitura crítica da classificação de atividades de vocabulário de Oxford e Scarcella (1994)}

Oxford e Scarcella (1994) definem três tipos de atividades de ensino de léxico, as descontextualizadas, as parcialmente contextualizadas e as plenamente contextualizadas. Aquelas que "extraem a unidade lexical o mais completamente possível de qualquer contexto comunicativo e significativo que pode ajudar o estudante a lembrar da palavra" (OXFORD E SCARCELLA, 1994, p. 237) são as chamadas descontextualizadas, cujos melhores representantes, para os autores, são as listas de palavras ${ }^{3}$, os flash cards e a consulta frequente ao dicionário.

\footnotetext{
${ }^{3}$ Utiliza-se o termo "palavra" nos casos de sintagmas lexicalizados como lista de palavras, agrupamento de palavras, associação de palavras, palavra-chave, palavras gramaticais e palavras lexicais.
} 
Defende-se que as listas de palavras, em geral organizadas por temas, não têm obrigatoriamente relação com o assunto tratado no capítulo do livro didático em que aparecem, mas, por outro lado, "permitem que o estudante 'aprenda' um grande número de significantes em um curto espaço de tempo"(OXFORD; SCARCELLA, 1994, p. 237), o que contribuiria, segundo os autores, para o sucesso em alguns exames, ainda que, na maioria das vezes, unidades lexicais memorizadas por meio de listas tendem a ser esquecidas rapidamente.

Apesar de as listas serem tradicionalmente utilizadas para que se apreenda um sentido único da unidade lexical, motivo pelo qual são mal avaliadas por Oxford e Scarcella (1994), elas podem ser mobilizadas em determinada prática de aula para que se reconheça a forma ortográfica da unidade lexical. Embora os autores identifiquem que as listas possam ser úteis quando, por exemplo, o aprendente estuda para fazer uma prova, não reconhecem que elas podem integrar uma atividade contextualizada. Um exemplo é a organização de um campo semântico por meio de método de análise semântica onomasiológica, que consiste na formação de um agrupamento de unidades lexicais relacionadas ao tema do texto previamente estabelecido. Ou mesmo o contrário, por meio do método de análise semântica semasiológico: a montagem da lista de unidades lexicais como exercício para que se determine o tema do texto (ULLMANN, 1964).

As atividades com flash cards consistem na cópia da unidade lexical de um lado de um cartão e de seu significado no outro lado. Com esse cartão em mãos, os alunos costumam fazer atividades diferenciadas que envolvem, por exemplo, brincadeiras de compra e venda, sorteio de cartões variados para que se adivinhe o significado ou a própria palavra.

A consulta frequente ao dicionário substituiria a inferência do sentido da unidade lexical desconhecida por meio do contexto. É o caso, para os autores, do aluno/leitor que suspende a leitura, a cada vez que encontra uma unidade lexical desconhecida, para consultar o dicionário e não o contexto. O que não consideram Oxford e Scarcella (1994) é que a utilização do dicionário pode promover a indução de sentido por meio dos recortes de uso de determinada unidade lexical, principalmente no caso de dicionários que tratam de apresentar um conjunto de usos. Por outro lado, os autores consideram o uso de dicionários que oferecem exemplos de palavras em contexto como atividades parcialmente contextualizadas, apesar de relativizarem sua qualidade, ao afirmarem que esses dicionários são problemáticos para estudantes (de língua estrangeira) de nível avançado, em função de oferecerem significados e funções típicas da unidade lexical, diferentemente do que alunos avançados almejariam, que seriam os significados e funções atípicas.

Já as atividades parcialmente contextualizadas são descritas por Oxford e Scarcella (1994) como aquelas que oferecem ao aluno "algum grau de contexto" (OXFORD; SCARCELLA, 1994, p. 238), dentre as quais destacam a classificação e a associação de palavras, as atividades com imagens visuais e imagens auditivas, o método da palavra-chave, a dramatização e o mapeamento semântico.

A classificação de palavras consiste na categorização de uma grande lista de palavras em listas menores organizadas por critérios semânticos (por exemplo, listas das palavras de amor); gramaticais (por exemplo, lista das palavras substantivas); ou 
discursivos (por exemplo, lista das palavras usadas para pedir desculpas), que se pode também denominar de campo semântico.

A associação de palavras é uma atividade em que se estabelece a relação entre uma unidade lexical nova e outra já conhecida, prática que contribui para que o aluno identifique as usuais relações sintagmáticas e paradigmáticas estabelecidas pelas unidades lexicais. Oferecem contexto significativo, porém restrito e incompleto.

Nessas atividades denominadas de parcialmente contextualizadas, Oxford e Scarcella (1994) quantificam o contexto: no título do tipo de atividade, usam o advérbio parcialmente para modificar o particípio (com valor adjetivo) contextualizadas em atividades parcialmente contextualizadas; para se referir a como o contexto aparece nessas atividades, usam o pronome adjetivo + substantivo algum grau, ao afirmarem que as atividades oferecem ao aluno algum grau de contexto, e, finalmente, os adjetivos restrito e incompleto, ao defenderem que a associação de palavras oferece um contexto significativo, porém restrito e incompleto.

Essa quantificação do contexto, que o torna maior ou menor, sugere que ele seria a própria prática social, e, portanto, uma atividade estaria mais ou menos próxima da prática social que a outra. Por sua vez, o vocabulário tratado fora de um texto pertencente a um gênero de uma esfera comunicativa real não estaria contextualizado, já que, segundo Oxford e Scarcella (1994), apenas a leitura é atividade verdadeiramente contextualizada. Entretanto, quando se leva um texto para a sala de aula, ele naturalmente se afasta da prática social de origem a qual está associado, deixando de ser "plenamente contextualizado", como defendem Oxford e Scarcella (1994), ao se referirem à prática de leitura de um texto.

Esse texto deixará de ser a materialização do gênero para comunicar, para ser o texto correspondente ao gênero para aprender, momento em que ocorre um desdobramento do gênero, que deixa de ser somente instrumento de comunicação para ser objeto de ensino-aprendizagem, levando o aluno a uma prática de linguagem que é parcialmente fictícia porque é instaurada com objetivo de aprendizagem (SCHNEUWLY; DOLZ, 2011, p. 65, 69), o que prova a inexistência dessa plenitude contextual.

Outras atividades consideradas parcialmente contextualizadas por Oxford e Scarcella (1994) são: atividades com imagens visuais que associam uma unidade lexical a uma imagem real ou à imagem que se tem, mentalmente, de algo da realidade. Acreditase que vendo a imagem ou apenas associando a unidade lexical a ela será mais fácil a sua retenção por parte do aluno. Atividades com imagens auditivas associam a nova unidade lexical com informações prévias do aluno relativas a rimas, acrônimos ou qualquer outra informação auditiva.

No método de palavra-chave combinam-se atividades de imagens visuais com as de imagens auditivas. A partir de uma palavra-chave, o aluno produz uma imagem visual e quanto mais tocante ela for, mais facilmente a unidade lexical será aprendida. O mesmo aconteceria com a criação de imagens auditivas que deveriam ser feitas a partir da exploração do significante da palavra-chave. 
A expressão corporal consiste na dramatização de uma determinada unidade lexical, prática mais apropriada para expressões de conteúdo mais concreto e menos apropriada para expressões abstratas.

Dentre as atividades parcialmente contextualizadas, o mapeamento semântico é a considerada mais completa por Oxford e Scarcella (1994), por envolver a associação de unidades lexicais e imagens visuais. Uma palavra-chave, disposta no meio de um gráfico, é ligada por linhas a outras associadas semanticamente, o que permite a visualização da relação das unidades lexicais do grupo.

Em todas essas quatro últimas atividades mencionadas (atividades com imagens visuais e auditivas, método de palavra-chave, expressão corporal e mapeamento semântico), categorizadas como parcialmente contextualizadas, os alunos acionarão seus conhecimentos prévios quando fizerem a leitura de uma imagem oferecida a eles ou mesmo quando organizarem um conjunto de saberes corporais para fazer a dramatização. Em nenhuma delas o contexto pode ser considerado parcial, se o tratamos como uma representação mental subjetiva que sempre será acionada pelos estudantes ao processarem o exercício.

Segundo Van Dijk (2012, p. 87), o contexto não é uma situação social objetiva, mas "construtos dos participantes da enunciação, subjetivos, embora socialmente fundamentados". Ele é uma construção mental dos sujeitos determinante no processamento e na coerência no discurso. As experiências e as situações cotidianas estão representadas nessas construções mentais, chamadas de modelo mental de contexto, o que faz delas a "base de construção das representações semânticas dos discursos sobre os eventos" (VAN DIJK, 2012, p. 91). Apesar de incorporarem muitos elementos socialmente compartilhados, esses modelos têm como base elementos pessoais, o que faz com que as interpretações costumem ser únicas. Esses modelos podem ser tratados também como a própria experiência dos indivíduos se se considerar a experiência como a interpretação do que ocorre com as pessoas. É esse entendimento de contexto como modelo mental essencialmente subjetivo que explica um texto escrito por pessoas diferentes sobre um mesmo evento ser diferente, contrapondo a ideia de que o discurso seria totalmente controlado pela situação social. Considerando que não é o contexto social isoladamente que definirá a interação do estudante com o texto, não existiria atividade plenamente contextualizada por si só, como sugerem Oxford e Scarcella (1994), já que o contexto depende da subjetividade dos interlocutores.

O que para Oxford e Scarcella (1994) seriam atividades ideais para ensino do léxico são as chamadas de atividades plenamente contextualizadas, aquelas que ofereceriam ao aluno a inserção integral em um contexto. Vê- se aí, mais uma vez, a quantificação do contexto, com o uso das unidades lexicais integral e plenamente, o que corrobora a ideia de que o contexto seria maior ou menor. Para os autores, essas atividades consistem na leitura de textos autênticos, a participação em interações significativas e que tenham propósitos definidos e, no caso da aprendizagem de língua estrangeira, incluem a audição de textos de falantes nativos. São as práticas incluídas no que se chama aprendizagem incidental do léxico: não se planejam exercícios, aprendem-se unidades lexicais em contextos de escrita e de fala, responsáveis por elucidar o sentido de desconhecidos itens lexicais. A ampla oferta de leitura é que promoverá, segundo Oxford e Scarcella (1994) frequentes encontros do leitor com a unidade lexical nova, ou com suas 
derivadas, assim como com as relações sintagmáticas e paradigmáticas que ela estabelece em sua atualização discursiva.

Tanto a integralidade contextual como a interação significativa com propósito definido desejadas por Oxford e Scarcella (1994) são bastante relativas, já que, ao ingressar na sala de aula, o gênero "funciona num outro lugar social, diferente daquele em que foi originado (...) e sofre, forçosamente, uma transformação" (SCHNEUWLY; DOLZ, 2011, p. 69), fazendo com que prevaleça seu traço de gênero para aprender sobre o traço gênero para comunicar, o que indica que o contexto dos gêneros não se restringe a sua fundamentação social de origem. Nessa perspectiva, nenhuma atividade dentre as elencadas por Oxford e Scarcella (1994) estaria mergulhada nesse desejado contexto pleno.

A leitura, aqui denominada por Oxford e Scarcella (1994) de atividade plenamente contextualizada, não poderá ser separada do que chamam de atividades parcialmente contextualizadas. Schneuwly e Dolz (2011, p. 87-88) defendem que uma atividade de escrita ou leitura deva ser decomposta em diversos elementos, inseridos no que chamam de módulos, para que se vá desenvolvendo diversas capacidades necessárias ao domínio de um gênero. No caso da classificação de Oxford e Scarcella (1994), as atividades como agrupamento, classificação de palavras ou mapeamento semântico, por exemplo, constituem atividades de decomposição de um texto objeto de leitura. Por isso, não devem ser consideradas apenas como ajuda para retenção do vocabulário já que são parte de uma atividade de leitura. Pode-se, por meio delas, desenvolver o conteúdo semântico, gramatical e discursivo da unidade lexical, assim como estabelecer relações entre essa unidade e as experiências do aprendente.

\section{Análise de exercícios de léxico em livros didáticos de português}

As atividades de sinonímia ou parassinonímia, de definição e de produção de pequenos textos com a utilização de uma unidade lexical nova, são mais frequentes em livros de PLE. Naquelas em que se solicitam sinônimos, as unidades lexicais são frequentemente retiradas de texto recém lido, o que torna o texto um pretexto para o ensino do léxico. Segundo a classificação adotada por Oxford e Scarcella (1994) e discutida na sessão anterior, esta atividade seria considerada parcialmente contextualizada. Um exemplo dessa atividade é o exercício extraído da obra Português Via Brasil: Um curso avançado para estrangeiros (LIMA; IUNES, 2005, p. 29), em que se pede para substituir expressões em negrito, retiradas de um texto recém estudado no capítulo, por outras com o mesmo sentido:

Atividade 1

"Substitua as expressões sublinhadas por outras com o mesmo sentido:

$1 \mathrm{O}$ negócio aconteceu num café.

2 Tinha uma porção de sujeitos sentados nesse café, tomando umas e outras.

3 Havia brasileiros, portugueses, franceses... o diabo.

4 De repente um alemão forte pra cachorro levantou...

5 Vai daí o alemão repetiu que não havia homem ali dentro pra ele.

6 Queimou-se então um português... 
7 ... e não conversou. Partiu pra cima do alemão.

8 Levantou-se então um inglês... e também entrou bem."

Tomando-se a primeira frase como exemplo, observa-se que a unidade lexical negócio possui muitas acepções resultantes da sua história de contextos. Como se defendeu na sessão anterior, o estudante acionará seu modelo contextual ao se deparar com a unidade lexical, mesmo que ela esteja fora de um texto. Entretanto, sem um contexto de produção e circulação claros, o aluno ficará restrito ao (s) contexto(s) que conhece, sem que se considere mais amplamente a polissemia, restringindo a palavra a contextos únicos. Isso consiste em prejuízo para a expansão vocabular, que não envolve apenas a ampliação do número de unidades lexicais conhecidas pelo aluno, mas, principalmente, das possibilidades de emprego dessas unidades.

No Dicionário de usos do Português do Brasil (BORBA, 2002, p. 1085), encontram-se inúmeras acepções para a unidade lexical negócio, das quais se apresentam abaixo três mais cabíveis aos possíveis contextos da frase "O negócio aconteceu num café":

1 "transação comercial: Fez o negócio porque a chácara era dele [...]; Corriam por ali muitas modalidades de negócio miúdo e graúdo [...]"

2 "atividade desconhecida, suspeita ou censurável: Não gosto deste negócio, não admito falta de respeito [...]. As viagens que o padre fazia meio misteriosas, era mesmo negócio de fêmea como ele suspeitava [...]."

3 “[...] trato: [...] Você não pode fazer negócio com os russos [...].”

Vê-se que, para substituir determinada expressão por outra com o mesmo sentido, como se solicita no exercício, ainda que o estudante ative seu conhecimento contextual, será necessário conhecer o contexto mais específico do uso de negócio, que o permita escolher dentre uma dessas acepções.

Em outro exemplo de atividade da mesma obra (LIMA; IUNES, 2005, p. 55), o aluno deve explicar algumas expressões idiomáticas:

Atividade 2:

"Explique:

1 nem a mais leve sombra de dúvida

2 receber tudo mastigado

3 cortar o mal pela raiz

4 levar um contra

5 torrar a paciência de alguém

6 sentir os pés formigando"

Explicar uma expressão idiomática pode ser uma forma de discutir os aspectos metafóricos nela presentes, de modo a perceber a ligação entre dois domínios semânticos como forma de contribuir para a compreensão dos interlocutores. Ao expandir o significado de uma unidade lexical para um nível mais abstrato, a metáfora colabora para a expressão do pensamento abstrato. 
A metáfora consiste na substituição de uma expressão denotativa por outra conotativa. Em "cortar o mal pela raiz", utiliza-se do campo semântico da natureza para que se construa a ideia de "aniquilamento de algum mal pelo início". O mal corresponde a um problema; raiz (da árvore) corresponde a início, e cortar corresponde a aniquilar ou extinguir. A comparação presente na expressão cortar o mal pela raiz é feita entre uma árvore doente e um mal humano.

Ao explicar as expressões idiomáticas e refletir sobre esses aspectos metafóricos, o estudante ressignifica tanto a expressão como as unidades lexicais que a compõem. Assim como no primeiro exercício, o aluno vai acionar seu modelo contextual, que é subjetivo, mas não vai ter oportunidade de expandir os contextos de uso da expressão.

No exercício seguinte (LIMA; IUNES, 2005, p. 22), o aluno deve criar um enunciado com determinada unidade lexical:

Atividade 3:

"Faça frases.

1 Dar conta do recado

2 Passar necessidade

3 Não ter remédio

4 Dar-se por satisfeito

5 Dar com

6 Errar de (de casa, de página...)

7 Pretender"

Se nos dois primeiros exercícios, exige-se do aluno um trabalho de recepção com acionamento dos seus modelos contextuais, nesse último exercício o trabalho deverá ser de produção. Ao sintagmatizar as unidades lexicais desse exercício, o aluno criará contextos com diferentes efeitos de sentido.

Ao se observar os enunciados das três atividades em sequência, tem-se a progressão de exercícios na seguinte ordem: sinonímia $\rightarrow$ definição $\rightarrow$ produção, como se vê abaixo:

Enunciado da atividade 1: Substitua as expressões sublinhadas por outras com o mesmo sentido

Exercício de sinonímia

Enunciado da atividade 2: Explique

Exercício de definição

Enunciado da atividade 3: Faça frases

Exercício de produção

Essa progressão sugere a intenção de que o aluno construa contextos. Ele deve se preparar para produzir frases por meio 1 da busca de equivalentes, no exercício de sinonímia, e 2 da explicação, no exercício de definição. Assim, no final do processo ele estaria apto para empregar unidades lexicais. 
O que se vê é que sem o contexto de circulação dessas unidades, o emprego delas estará restrito ao contexto que o aluno já conhece, o que contribui novamente para uma prática restrita de conhecimento lexical em que não se privilegia a expansão dos contextos de uso.

As três atividades privilegiam a dimensão semântica da unidade lexical, sem considerar a gramatical e a discursiva. Na primeira atividade, as unidades estudadas são extraídas de um texto recém-lido que serve apenas como pretexto para o ensino do vocabulário. Nas outras duas atividades, elas não estão relacionadas a nenhum texto.

Já a maioria das obras de PLM da atualidade tem se alinhado às orientações dos documentos educacionais da área de Linguagens (BRASIL, 1998, 2000, 2002, 2006), apoiados na concepção sociointeracionista, segundo a qual o sentido da linguagem depende das relações entre interlocutores, texto e sociedade.

Diferentemente das atividades de léxico do livro PLE recém apresentadas, a maioria dos exercícios de léxico das obras de PLM atuais tendem a levar o aluno à reflexão sobre a unidade lexical no próprio texto em que ela está atualizada. Alguns exemplos podem ser vistos na obra Conecte Texto e Interação (CEREJA; COCHAR, 2013, p.138-139) no capítulo intitulado $O$ debate regrado público. Apresenta-se a crônica O pavão, de Rubem Braga, seguida de algumas atividades, dentre as quais destacamos duas.

Segue o texto e as duas atividades:

“O Pavão

Rubem Braga

"Eu considerei a glória de um pavão ostentando o esplendor de suas cores; é um luxo imperial. Mas andei lendo livros, e descobri que aquelas cores todas não existem na pena do pavão. Não há pigmentos. O que há são minúsculas bolhas d'água em que a luz se fragmenta, como em um prisma. $O$ pavão é um arco-íris de plumas.

Eu considerei que este é o luxo do grande artista, atingir o máximo de matizes com o mínimo de elementos. De água e luz ele faz seu esplendor; seu grande mistério é a simplicidade.

Considerei, por fim, que assim é o amor, oh! minha amada; de tudo que ele suscita e esplende e estremece e delira em mim existem apenas meus olhos recebendo a luz de teu olhar. Ele me cobre de glórias e me faz magnífico."

Atividade 1

"Observe como o autor começa os parágrafos de seu texto:

'Eu considerei

Eu considerei

Considerei, por fim'

Discuta com seu professor e seus colegas: A repetição da mesma forma verbal em todos os parágrafos deixa o texto truncado, empobrecendo-o? Justifique sua resposta." 
Nesse exemplo, o autor chama a atenção para a repetição da forma verbal considerei como recurso para criar um efeito de sentido: a repetição cria o paralelismo que garante ritmo e unidade ao texto. Nas observações que faz ao professor, o autor também recomenda que se discuta com o aluno que o recurso da repetição é usual e recomendado no texto literário, o que demonstra preocupação da adequação da escolha lexical ao gênero discursivo.

Atividade 2

"Releia o trecho abaixo:

'Assim é o amor, oh! Minha amada; de tudo o que ele suscita e esplende e estremece e delira em mim'

a) o termo assim pode tanto retomar algo que já foi dito quanto anunciar o que ainda será dito. Qual é a função dele no trecho lido?

b) Há no trecho uma repetição do conectivo $e$. Pode-se dizer que essa repetição é prejudicial à leitura deixando o trecho pouco coeso? Discuta com seu professor e colegas e concluam. Qual é o efeito dessa repetição para o texto?"

No exercício $a$ enfatizam-se as relações que assim estabelece com outros termos da oração, assumindo ora função anafórica, ora catafórica. É uma forma de ensinar que o sentido da unidade lexical não está pronto, mas se estabelece nas relações construídas no enunciado. Já no exercício $b$, o autor do livro didático chama atenção para os efeitos de sentido que a repetição do conectivo $e$ pode gerar e sugere que alunos e professor discutam sobre a escolha do enunciador, o que faz com que o entendimento sobre a repetição do conectivo seja estabelecido na interação entre autor, texto e leitor, em um processo de negociação de sentidos.

O que se pode observar nessas atividades é que o léxico está contextualizado não apenas nas relações estabelecidas entre palavras no interior do enunciado, mas também entre escolha vocabular e gênero discursivo e entre escolha vocabular e interlocutores.

A atividade de leitura apresentada a seguir acompanha e amplia os princípios implícitos nas atividades analisadas na obra de PLM porque enfatiza o caráter pluridimensional do léxico ao tratar de seu conteúdo semântico, gramatical e discursivo.

\section{Ensino do léxico em uma prática de leitura}

Diferentemente do que se defendeu na tradição mais antiga de ensino de língua, segundo a qual o texto detinha o sentido a ser desvendado pelo leitor, em uma tradição mais recente a construção do sentido depende da relação entre autor, texto e leitor. Segundo Leffa (1999), na chamada perspectiva do texto, inserida nas teorias da leitura, predominante nas décadas de 1950 e 1960, o texto era tratado como objeto transparente que revelava o conteúdo de maneira clara, de modo que a construção de significado se daria apenas pela extração de informação do texto. Já na perspectiva do leitor, considerava-se que o leitor é que atribuía sentido ao texto com base em suas diferentes fontes de conhecimento (linguístico, textual e enciclopédico). $\mathrm{Na}$ mais recente perspectiva interacional, o sentido do texto seria constituído não apenas pelo texto ou pelo leitor, mas na relação entre autor, texto e leitor. 
O conhecimento de uma unidade lexical envolve mais do que a apreensão do significado, como sugere a tradição mais antiga. Envolve o conhecimento da polissemia, das convencionais relações sintagmáticas que a unidade lexical estabelece, assim como das informações fonológicas, morfológicas, sintáticas nela contidas e, no nível do discurso, da sua adequabilidade estilística (BASSO, 2007). Nation (1990) acrescenta o conhecimento da forma falada e escrita, das configurações e da colocabilidade (colocações habituais da unidade lexical), da sua frequência e do registro, do ponto de vista da variação. Para Leffa (2000) conhecer uma unidade lexical é conhecer a probabilidade de sua ocorrência; as unidades lexicais que podem e costumam acompanhar outras (colocabilidade); os principais compostos formados por elas; as restrições de registro da unidade lexical, suas derivações e flexões, a classe gramatical a que pertence, as relações paradigmáticas que estabelece e seus valores denotativos e conotativos.

Apresenta-se a seguir uma prática de leitura do texto "Da felicidade" (Quintana, 1997), com ênfase no léxico, em que se propõe a exploração do contexto do leitor, seguida de atividades direcionadas ao vocabulário do texto, com ênfase em seus aspectos semânticos, gramaticais e discursivos com a intenção de levar o aluno ao conhecimento pluridimensional da unidade lexical (BASSO, 2007; NATION, 1990; LEFFA, 2000).

\subsection{Antecipação do léxico de "Da felicidade", de Mário Quintana}

\section{"Da felicidade}

Quantas vezes a gente, em busca da ventura

Procede tal e qual o avozinho infeliz:

Em vão, por toda parte, os óculos procura

Tendo-os na ponta do nariz!"

Mário Quintana

Tanto em aulas de PLE como de PLM, pode-se antecipar a inserção do texto, antes de sua chegada em versão impressa ou virtual, por meio da conversa entre alunos e professor, em que se pode tratar do tema do texto a ser introduzido mais tarde, ou mesmo de um recurso linguístico nele presente. O objetivo é atingir o contexto do aluno e não exclusivamente do texto que se pretende ler, o que garantirá a participação do leitor no processo de construção do sentido, além de já começar a introdução de um determinado léxico que se queira estudar.

No caso de "Da felicidade", o tema a ser tratado é a busca ansiosa pela felicidade. O professor iniciará a leitura antes de oferecer o texto aos alunos, antecipando, por exemplo, o tema por meio de uma conversa sobre o estado de espírito dos alunos naquele dia, por meio de perguntas ou afirmações: Vocês estão bem hoje? Parecem um pouco tristes, ou Parecem alegres, animados, felizes. A depender das respostas dadas pelos alunos, algumas perguntas servem para antecipar certos sentidos que o texto evocará, por exemplo: O que é felicidade? Onde encontrá-la? Em que situações você se sente feliz? 
É difícil encontrar a felicidade?. A partir das respostas, encaminha-se a leitura/debate para a relação entre ansiedade e felicidade, que já está sugerida no texto. O professor conduzirá o debate ao tema da perseguição da felicidade, assunto tratado no texto. Uma antecipação das escolhas lexicais-chave do texto deve estar nessa conversa inicial (etapa em que os alunos ainda não tiveram contato com o texto), fase de estudo do texto em que o léxico começa a ser introduzido pelos interlocutores da conversa: pelo professor, que tem a intenção de ensinar um conjunto lexical específico; pelos alunos, que farão escolhas novas que poderão dialogar com aquelas já previstas pelo professor.

O professor já terá estudado o léxico do texto de maneira sistemática e direta, considerando o conhecimento pluridimensional da unidade lexical, como suas frequentes relações paradigmáticas e sintagmáticas, sua formação e suas restrições de uso.

Na conversa que precede a leitura do texto "Da felicidade", podem estar presentes as seguintes unidades lexicais: o substantivo felicidade, inserido no sintagma busca de felicidade, para que se prepare o estudo de parassinônimos do texto como busca de ventura; o adjetivo infeliz e o antônimo feliz, que posteriormente será exemplo para que se trate da antonímia em pares opositivos de mesmo radical, formados por prefixação; a conjunção subordinativa tal e qual, que aparecerá no texto e que, mais tarde, será substituída por parassinônimas, num exercício de exploração das relações paradigmáticas.

As unidades lexicais destacadas na conversa inicial serão estudadas com pormenor depois de lido o texto, etapa em que serão analisadas como escolhas lexicais: unidades léxico-gramaticais atualizadas, estudadas em sua pluridimensionalidade, com ênfase aos aspectos gramaticais, semânticos e discursivos determinantes na constituição do sentido da palavra.

\subsection{A pluridimensionalidade do léxico em "Da felicidade", de Mário Quintana}

O costume de tratar exclusivamente o aspecto semântico estrito das unidades lexicais, nas práticas escolares, criou nos alunos a impressão de que conhecer uma unidade lexical é conhecer seu significado, o que reforça a falsa crença na monossemia. Há um conjunto de dimensões dessa unidade que, apenas reunidas, poderão levar o aluno/leitor a conhecê-la adequadamente, com condições de mobilizá-la socialmente em suas relações discursivas ulteriores.

Quando conhecemos uma unidade lexical, aprendemos que ela integra um paradigma formado por outras que podem se atualizar em contextos semelhantes. Normalmente chamado de campo semântico, campo lexical ou campo léxico-semântico, esse paradigma é formado por lexemas que dividem uma zona de significação comum e se apresentam em oposição uns com os outros (COSERIU, 1977). Pode também ser definido como paradigma formado por um contínuo de conteúdo lexical, repartido em lexemas que se opõem entre si pelos semas (VILELA, 1994). 
Organizar um campo semântico em uma prática de ensino de léxico é revelar as relações paradigmáticas que as unidades lexicais costumam estabelecer e assim obter uma visão mais ordenada das escolhas lexicais de um texto que refletem determinados recortes culturais da língua ou mesmo dos enunciadores. É também uma forma de confirmar as intenções dos interlocutores que sempre estarão marcadas na escolha das unidades lexicais do campo.

O professor mostrará as relações paradigmáticas entre unidades que aparecerem tanto na conversa inicial com os alunos, quanto no momento da leitura do texto. Esses leitores perceberão que o sentido delas também se constrói na relação que estabelecem no paradigma. No ensino da língua estrangeira, por exemplo, poderá ser analisada qual unidade lexical tem significado similar na língua materna do aluno e se ela se insere ou não no mesmo paradigma.

Determinadas as relações paradigmáticas, para que se conheça uma unidade lexical é necessário conhecer propriedades gramaticais que governam seu uso, como os tipos de relação gramatical que a unidade estabelece e as restrições gramaticais desse uso. Para Rio-Torto (2006), diferentemente de uma longa tradição que tratou léxico e gramática como módulos da língua totalmente dissociados, uma reflexão mais contemporânea trata as duas disciplinas como faces da mesma realidade. O estudo dos signos da língua, sejam palavras lexicais ou palavras gramaticais, norteia-se pelas propriedades gramaticais que os definem e que condicionam seu próprio comportamento discursivo. O léxico definese por sua natureza pluridimensional que envolve a morfologia da unidade lexical, sua semântica e sintaxe interna e externa, e sua atualização discursiva.

Destacam-se a seguir alguns recortes de relações paradigmáticas e de propriedades gramaticais e discursivas no léxico do texto "Da felicidade", de Mário Quintana (1997).

"Da felicidade

Quantas vezes a gente, em busca da ventura, Procede tal e qual o avozinho infeliz:

Em vão, por toda parte, os óculos procura

Tendo-os na ponta do nariz!"

No contexto de "Da felicidade", as unidades lexicais "felicidade", "ventura", "óculos" e "ponta do nariz" podem se agrupar no campo semântico da felicidade. "Felicidade" e "ventura" são parassinônimas claras: "felicidade" é alegria, contentamento; "ventura" é felicidade, fortuna boa ou sorte boa. "Óculos" e "ponta do nariz" compartilham traços comuns de significado com "felicidade" e "ventura" no contexto de "Da felicidade": os "óculos" são o objeto da busca ansiosa, assim como a "ventura" também é buscada; a "ponta do nariz" é o lugar onde estão os óculos e o lugar tão próximo de cada um de nós onde se encontraria a tão almejada felicidade.

Ressaltem-se as unidades lexicais que acompanham "ventura" e "óculos" que devem ser objeto de estudo do léxico, ao se tratar das relações sintagmáticas que as unidades lexicais estabelecem: "o avozinho os óculos procura" e "a gente em busca da 
ventura". Procura (verbo) e em busca de (locução adverbial) são parassinônimos a serem destacados na análise do léxico, com atenção para a categoria gramatical de cada unidade lexical: se a busca da ventura aparece por meio da locução adverbial "em busca de", a procura dos óculos aparece por meio do verbo conjugado no presente do indicativo, terceira pessoa do singular "procura", tendo como sujeito o "avozinho". Essa escolha gramatical feita pelo enunciador, se destacada no ensino do léxico, contribui para a ampliação do repertório léxico do aluno, porque indica que é possível escolher não exclusivamente no nível semântico, mas também no gramatical, instância determinante na constituição do sentido lexical.

O enunciado "Quantas vezes a gente, em busca da ventura, procede tal e qual ..." poderia ser atualizado como

1 "Quantas vezes a gente, ao buscar ventura, procede tal e qual ...", em que "ao buscar ventura" é oração subordinada reduzida de infinitivo;

2 "Quantas vezes a gente, quando busca ventura, procede tal e qual...", em que "quando busca ventura" é oração subordinada conjuntiva;

3 "Quantas vezes a gente, buscando ventura, procede tal e qual...", em que "buscando ventura" é oração subordinada reduzida de gerúndio.

As expressões destacadas em itálico nos exemplos acima são alternativas gramaticais para "em busca de", que é a escolha feita pelo enunciador. O que é preciso ensinar e aprender é que cada uma delas pode contribuir para que se crie determinado efeito de sentido que se queira instaurar no ato da interlocução. Assim, a escolha por $a o$ buscar (1) e quando busca (2), oração reduzida de infinitivo e oração conjuntiva, respectivamente, enfatizam a ação pontual de buscar, sendo que ao buscar (1) parece referir-se diretamente ao início dessa ação, enquanto quando busca (2) limita-se à ação pontual sem clareza quanto ao seu início. No caso da oração reduzida de gerúndio buscando ventura (3), há indicação da ação em curso, inacabada. $\mathrm{O}$ que se vê nessas paráfrases é a propriedade gramatical que condiciona o caráter discursivo da unidade lexical (RIO-TORTO, 2006). O exercício com essas alternativas léxico- gramaticais remexem, processam e manipulam a palavra de forma a garantir que ela integre a rede lexical do aluno (LEFFA, 2000).

A estrutura derivacional da unidade lexical "avozinho" também será exemplo de discussão sobre o caráter discursivo que se constrói por meio da propriedade gramatical. O sufixo diminutivo "inho", atrelado ao radical "avô", confere fragilidade ao avô, acentua sua velhice, além de situá-lo em um universo de senilidade, o que não é feito exclusivamente pelo sufixo, mas na sua aliança com o contexto linguístico: “... o avozinho infeliz... por toda parte, os óculos procura...", o que sugere uma dificuldade de o avô encontrar as coisas pelo declínio do funcionamento da memória, um dos traços da senilidade.

O adjetivo "infeliz", modificador de avozinho, é antônimo de feliz, adjetivo correspondente ao substantivo "felicidade", que dá nome ao poema. O mesmo radical feliz forma os pares opositivos feliz e infeliz por prefixação. O avozinho é infeliz porque vive uma busca vã. A unidade lexical "infeliz", modificadora de avozinho, será analisada junto com "avozinho": por meio dos afixos (prefixo in, em "infeliz" e sufixo inho, em "avozinho") é que se constrói a imagem de fragilidade e declínio do avô. Se inho é 
declínio, fragilidade, senilidade do avô; in é a ausência e a impossibilidade de felicidade. Ambos recursos comprovam mais uma vez que a propriedade gramatical atua na constituição do discurso.

A conjunção subordinativa "tal e qual", em "Procede tal e qual o avozinho infeliz", é responsável pela relação de comparação estabelecida que equipara "a gente" ao triste avô, ao buscarmos a felicidade. É possível que outras conjunções comparativas sejam testadas para uso no mesmo enunciado, como forma de compor um repertório léxicogramatical com os alunos e de verificar possíveis efeitos de sentido constituídos por elas. As seguintes alternativas seriam possíveis: "Procede como o avozinho infeliz", "procede igual ao avozinho infeliz", "procede assim como o avozinho infeliz" e "procede bem como o avozinho infeliz".

O elemento adverbial deslocado "em vão", em "Em vão, por toda parte, os óculos procura", ilustrará o valor da ordem na construção do efeito de sentido, para a qual Nation (1990) chama a atenção, ao destacar cada aspecto envolvido no conhecimento de uma palavra. Ao trazer "em vão" para o início do verso, enfatiza-se o efeito discursivo da impossibilidade do alcance da felicidade. Antes mesmo de o interlocutor conhecer o objeto da busca do "avozinho", já sabe que será uma busca "em vão".

\section{Considerações finais}

As orientações de Oxford e Scarcella (1994), das quais parte a análise realizada neste artigo, comportam três modelos de atividades para o ensino do léxico, que vão desde as práticas de ensino de palavras isoladas, escolhidas aleatoriamente para compor uma unidade de ensino, chamadas pelos autores de atividades descontextualizas, até aquelas que ofereceriam ao aluno inserção integral em um contexto significativo, denominadas pelos autores de atividades plenamente contextualizadas.

Tratou-se de apresentar, neste artigo, uma releitura dessa classificação e da visão de contexto subjacente a ela. Para isso, utilizaram-se os fundamentos de Van Dijk (2012) para quem o contexto é um modelo mental subjetivo, composto pelas experiências subjetivas influenciadas pelas práticas sociais. Nessa releitura discutiu-se que, diferentemente do que defendem Oxford e Scarcella (1994), em atividades tradicionalmente consideradas descontextualizadas, como por exemplo, em listas de palavras usadas para o ensino do léxico, o contexto do estudante sempre será acionado no momento em que ele interage com a atividade. Por outro lado, constatou-se que atividades de sinonímia, definição e produção de frases da obra de PLE (LIMA; IUNES, 2005), exemplificadas na sessão 2, permitem o ativamento do contexto do estudante, mas se restringem a ele, impedindo assim a ampliação do conhecimento de outros contextos da unidade lexical.

Ainda na sessão 2, observou-se que atividades de ensino de léxico na obra de PLM utilizada (CEREJA; COCHAR, 2013) oferecem o contexto de circulação da unidade lexical e, por meio dos exercícios propostos, estimulam o estudante a observar relações estabelecidas pela unidade lexical atualizada com vistas a expandir o conhecimento do emprego do léxico. 
Na sessão 3, apresentou-se uma prática de leitura com ênfase no léxico de "Da felicidade", de Mário Quintana, por meio da qual se mostrou que uma abordagem pluridimensional do léxico, como propõem Nation (1990) e Leffa (2000), por exemplo, e que envolve o conhecimento do componente semântico e gramatical, e das condições de uso da palavra, levará o aluno a se apropriar de diferentes aspectos linguísticosdiscursivos que constituem a unidade lexical e que contribuem para a constituição de sentido. O estudo da unidade lexical partirá do conhecimento que o aluno já tem sobre ela, que é ativado pelo professor, seguido da análise das suas relações paradigmáticas e sintagmáticas e dos componentes gramaticais que a constituem, percurso por meio do qual se converterá a unidade lexical em escolha lexical, evidenciando seu caráter discursivo.

Em toda a análise dos exercícios da obra de PLE (LIMA; IUNES, 2005) e de PLM (CEREJA; COCHAR, 2013), e na apresentação de uma prática de leitura com ênfase ao léxico do texto "Da felicidade", procurou-se refletir sobre quais atividades proporcionam maior expansão do conhecimento lexical, priorizando o uso da unidade lexical. O que se conclui é, que apesar de o trabalho do léxico na leitura oferecer maior possibilidade de ampliação do saber lexical, está certo que não existe aprendizado integral dos contextos de uso da unidade lexical, uma vez que em cada uma de suas atualizações discursivas, o sentido lexical será determinado na relação entre o contexto de produção, de circulação e de recepção que é singular, sem contar as também singulares relações entre modelos contextuais subjetivos dos interlocutores e relações linguístico-gramaticais e extralinguísticas que a unidade lexical estabelece no uso.

\section{Referências}

BASSO, J.P. Níveis de conhecimento lexical resultantes da aquisição incidental de vocabulário por meio da leitura extensiva. Em: SCARAMUCCI, M.V.R.; GATTOLIN, S.R.B. (Orgs.). Pesquisas sobre vocabulário em língua estrangeira. Campinas: Mercado de Letras, 2007. p. 97-126.

BORBA, F. da S. Dicionário de usos do Português do Brasil. São Paulo: Ática, 2002.

BRASIL. Ministério da Educação. Parâmetros Curriculares Nacionais do ensino médio: parte II: Linguagens, Códigos e suas Tecnologias. Brasília, DF: Secretaria de Educação Básica, 2000.

BRASIL. Ministério da Educação. Parâmetros Curriculares Nacionais do ensino médio. Orientações educacionais complementares aos Parâmetros Curriculares Nacionais: Linguagens, Códigos e suas Tecnologias. Brasília, DF: Secretaria de Educação Básica, 2002.

BRASIL. Ministério da Educação. Parâmetros Curriculares Nacionais do ensino médio. Orientações curriculares para o ensino médio: Linguagens, Códigos e suas Tecnologias. Brasília, DF: Secretaria de Educação Básica, 2006. 
BRASIL. Ministério da Educação. Parâmetros Curriculares Nacionais do terceiro e quarto ciclos do ensino fundamental: Língua portuguesa. Brasília, DF: Secretaria de Educação Fundamental, 1998.

CEREJA, W.; COCHAR, T. Conecte Texto e Interação. São Paulo: Saraiva, 2013.

COSERIU, E. Princípios de semántica estructural. Madrid: Editorial Gredos, 1977.

LEFFA, V.J. As palavras e sua companhia. O léxico na aprendizagem das línguas. Pelotas: Educat, 2000.

Perspectivas no estudo da leitura. Texto, leitor e interação social. Em: LEFFA, V.J.; PEREIRA, A.E. (Orgs.) O ensino da leitura e produção textual. Alternativas de renovação. Pelotas: Educat, 1999. p. 13-37.

LIMA, E.E.O.F.; IUNES, S.A. Português via Brasil: um curso avançado para estrangeiros. São Paulo: EPU, 2005.

NATION, P.I.S. Teaching and learning vocabulary. Boston: Heinle \& Heinle, 1990.

OXFORD, R.L.; SCARCELLA, R.C. Second language vocabular learning among adults: state of the art in vocabular instruction. SYSTEM, v. 22, n. 2, 231-243, 1994. Disponível em http://www.sciencedirect.com/science/article/pii/0346251X94900590. Acesso em $12 / 05 / 2017$.

QUINTANA, Mário. Poesias. 7ª ed. Rio de Janeiro: Globo, 1997.

RIO-TORTO, G. O léxico: semântica e gramática das unidades lexicais. Em: ATHAYDE, M.F. Estudos sobre léxico e gramática. Coimbra: CIEG/FLUC, 2006. 11-34. Disponível em http://docplayer.com.br/1788780-O-lexico-semantica-e-gramatica-das-unidadeslexicais.html. Acesso em 12/05/2017.

RODRIGUES, D.F. Visões sobre ensino-aprendizagem de vocabulário em aulas de ILE. Em: SCARAMUCCI, M.V.R.; GATTOLIN, S.R.B. (Orgs.). Pesquisas sobre vocabulário em língua estrangeira. Campinas: Mercado de Letras, 2007. 15-37.

SCARAMUCCI, M.V.R. A competência lexical de alunos universitários aprendendo a ler em inglês como língua estrangeira. Em: SCARAMUCCI, M.V.R.; GATTOLIN, S.R.B. (Orgs.). Pesquisas sobre vocabulário em língua estrangeira. Campinas: Mercado de Letras, 2007. 73-96.

SCHNEUWLY, B.; DOLZ, J. Gêneros orais e escritos na escola. $3^{\text {a }}$. ed. Campinas: Mercado de Letras, 2011.

UCHÔA, C.E.F. Tradição e inovação no ensino de língua e de literatura. CONFLUÊNCIA, n. 37/38, p. 43-57, Rio de Janeiro, 2009. Disponível em http://llp.bibliopolis.info/confluencia/pdf/52.pdf . Acesso em 12/05/2017. 
ULLMANN, S. Semântica. Uma introdução à ciência do significado. Lisboa: Fundaçao Calouste Gulbekian, 1964.

VAN DIJK, T.A. Discurso e contexto. Uma abordagem sociocognitiva. São Paulo: Contexto, 2012.

VILELA, Mário. Estudos de Lexicologia do Português. Coimbra: Almedina, 1994.

$$
* * *
$$

Artigo recebido em: maio de 2017.

Aprovado e revisado em: outubro de 2017.

Publicado em: novembro de 2017.

\section{Para citar este texto:}

GIL, Beatriz Daruj. A pluridimensionalidade do léxico em práticas de ensino de português. Entremeios [Revista de Estudos do Discurso, on-line, www.entremeios.inf.br], Seção Estudos, Programa de Pós-Graduação em Ciências da Linguagem (PPGCL), Universidade do Vale do Sapucaí (UNIVÁS), Pouso Alegre (MG), vol. 15, p. 13-30, jul. - dez. 2017.

DOI: http://dx.doi.org/10.20337/ISSN2179-3514revistaENTREMEIOSvol15pagina13a30 